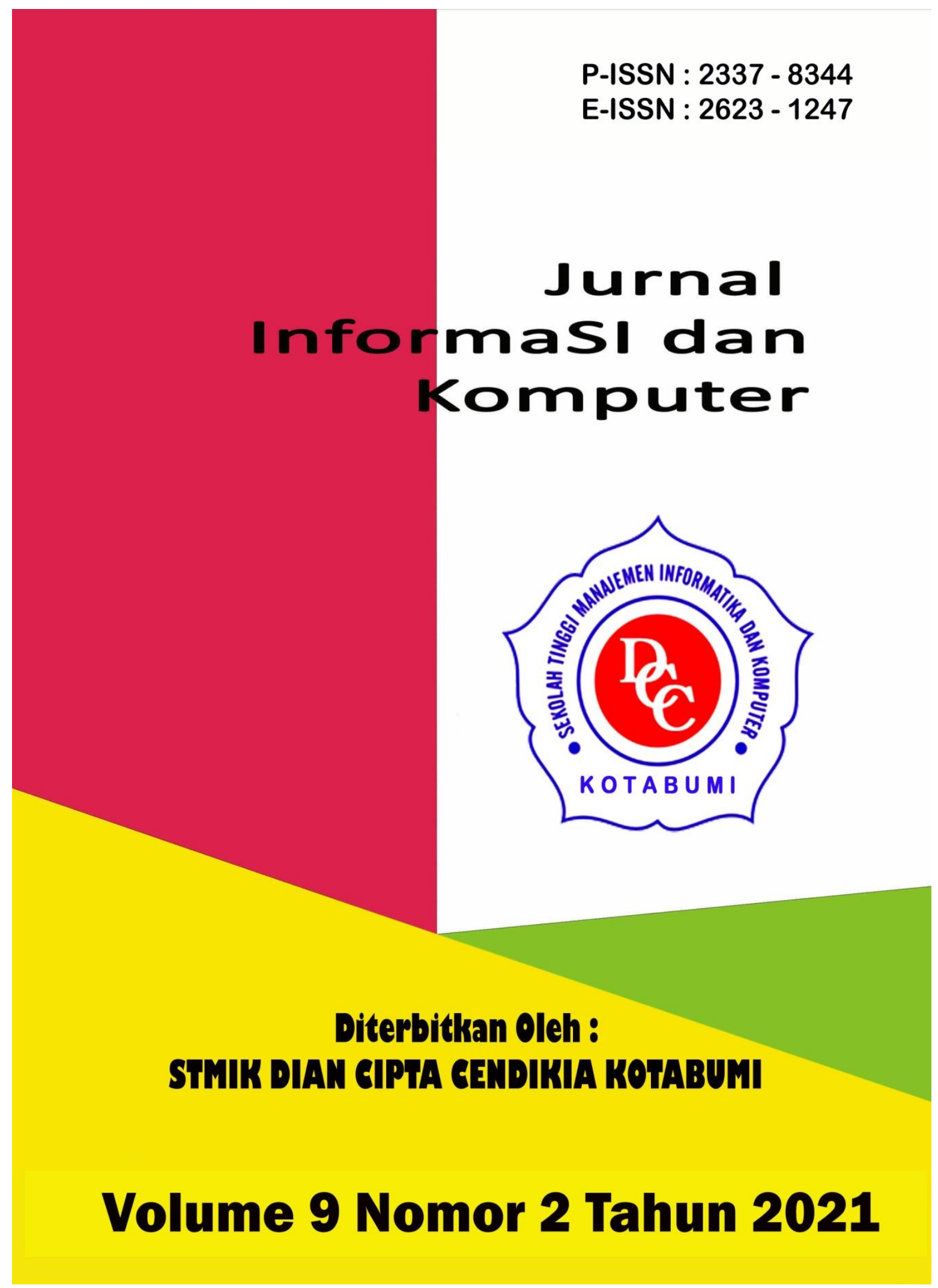


Penerbit Lembaga Penelitian STMIK Dian Cipta Cendikia Kotabumi Hak atas naskahh/tulisan tetap berada pada penulis, isi diluar tangung jawab penerbit dan Dewan Penyunting 


\section{PENGANTAR REDAKSI}

Puji syukur dipanjatkan kehadirat Tuhan Yang Maha Esa, atas karunia dan limpahan rahmatNYA jualah Jurnal Informasi dan komputer (JIK) STMIK Dian Cipta Cendikia Kotabumi ini dapat terwujud.Jurnal Informasi dan Komputer (JIK) yang terbit dua (2) kali dalam setahun ini merupakan suatu wadah untuk penyebar luasan hasil-hasil penelitian, studi pustaka, karya ilmiah yang berkaitan dengan Informasi dan Komputer khususnya bagi dosen-dosen STMIK Dian Cipta Cendikia Kotabumi serta umumnya para cendikiawan, praktisi, peneliti ilmu Informatika dan Komputer.

Harapan, dengan diterbitkannya Jurnal Informasi dan Komputer (JIK) ini sebagai salah satu bentuk sumbangan pemikiran dalam pengembangan ilmu informatika dan komputer yang berkaitan dengan kajian-kajian di bidang tekhnologi Informatik, Komunikasi Data dan Jaringan Komputer, perancangan dan Rekayasa Perangkat Lunak, serta ilmu-ilmu yang terkait dengan bidang Informasi dan Komputer lainnya.

Berkenaan dengan harapan tersebut, kepada para peneliti, dosen dan praktisi yang memiliki hasil-hasil penelitian, kajian pustaka, karya ilmiah dalam bidang tersebut diatas, dengan bangga redaksi Jurnal Informasi dan Komputer (JIK) menerima naskah ringkasan untuk dimuat pada jurnal Informasi dan Komputer (JIK) STMIK Dian Cipta Cendikia Kotabumi dengan berpedoman pada penulisan naskah jurnal sebagaimana dilampirkan pada halaman belakang (Bagian kulit dalam) buku jurnal ini.

Mutu dari suatu jurnal ilmiah tidak hanya ditentukan oleh para pengelolanya saja, tetapi para penulis dan pembaca jualah yang mempunyai peranan besar dalam meningkatkan mutu jurnal Informatika dan Komputer ini. Merujuk pada realita ini kamu sangat mengharapkan peran aktif dari peneliti untuk bersama-sama menjaga dan memelihara keberlangsungan dari jurnal Informasi dan Komputer STMIK Dian Cipta Cendikia Kotabumi ini. Yang juga tidak kalah pentingnya dari partisipasi tersebut diatas, adalah saran dan kritik yang membangun dari pembaca yang budiman agar kiranya dapat disampaikan langsung kepada redaksi JIK. Saran dan kritik yang membangun akan dijadikan masukan dan pertimbangan yang sangat berarti guna peningkatan mutu dan kualitas Jurnal Informasi dan Komputer STMIK Dian Cipta Cendikia Kotabumi.

Tak lupa diucapkan terima kasih yang tak terhingga atas perhatian dan kerjasama dari semua pihak yang tak dapat disebutkan satu persatu hingga dapat diterbitkan nya Jurnal Informasi dan Komputer (JIK) STMIK Dian Cipta Cendikia Kotabumi. Semoga apa yang telah diperbuat untuk kebaikan akan menjadi amal ibadah, amin.

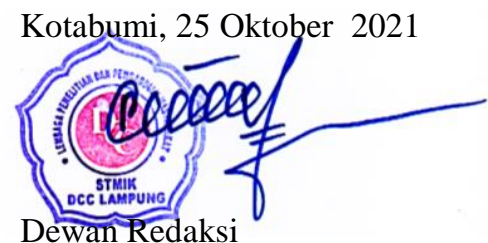




\section{JURNAL INFORMASI DAN KOMPUTER}

Volume 9 Nomor 2 Oktober 2021

Jurnal Informasi dan Komputer merupakan Sarana informasi ilmu pengetahuan, Tekhnologi dan Komunikasi yang berupa hasil penelitian, tulisan ilmiah, Ataupun studi pustaka. Jurnal ini terbit dua kali setahun pada bulan April dan Oktober. Berisi hasil penelitian ilmiah di bidang informatika yang bertujuan untuk menghubungkan adanya kesenjangan antar kemajuan teknologi dan hasil penelitian. Jurnal ini di terbitkan pertama kali pada tahun 2013.

Penanggung Jawab:

Ketua STMIK Dian Cipta Cendikia Kotabumi

\section{Pembina:}

Ketua STMIK Dian Cipta Cendikia Kotabumi Ketua Lembaga Penelitian STMIK Dian Cipta Cendikia Kotabumi

\section{Pimpinan Redaksi}

Dwi Marisa Efendi,.S.Kom.,M.Ti

\section{Redaksi pelaksana}

Rustam,.S.Kom,.M.Ti (STMIK Dian Cipta Cendikia Kotabumi)

Nurmayanti M.Kom (STMIK Dian Cipta Cendikia Kotabumi)

Sukatmi,.S.Kom., M.Kom (AMIK DCC Bandar Lampung)

Sampurna Dadi Riskiono,M.Kom (Universitas Teknokrat Indonesia)

Ifo Wahyu Pratama,S.Kom.,M.Ti(AMIK MASTER Lampung)

\section{Mitra Bestari}

Dr. RZ. ABDUL AZIZ, ST., MT (Institut Informatika dan Bisnis Darmajaya)

Dr. Dadang Sudrajat, S.Si, M.Kom (STMIK IKMI Cirebon)

Dr. Septafiansyah Dwi Putra, S.T., M.T (Politeknik Negeri Lampung)

Dr. Evi Grativiani, S.E., M.S.I (Universitas Sebelas Maret)

Rohmat Indra Borman ( Universitas Teknokrat Indonesia )

Ferry Wongso, S.KOm., M.Kom ( STMIK Darma Pala Riau)

Ferly Ardhy, S.Kom., M.Ti ( Universitas Aisyah Pringsewu )

Firmansyah, S.E., M.Si (STMIK Darma Pala Riau)
Amarudin (Universitas Teknokrat Indonesia)

Didi Susianto, S.T., M.Kom (AMIK Dian Cipta Cendika Bandar Lampung)

Alhibarsyah, St., M.Kom (STMIK Tunas

Bangsa Bandar Lampung)

Kemal Farouq Mauladi, S.Kom .M.Kom (Universitas Islam Lamongan)

Rima Mawarni, M.Kom ( STMIK Dian Cipta Cendikia Kotabumi)

Wira Jaya Hartono, S.Pd., M.Pd ( STMIK Darma Pala Riau)

Penerbit : STMIK Dian Cipta Cendikia Kotabumi Bekerja Sama Dengan LPPM STMIK Dian Cipta Cendikia Kotabumi.

\section{Alamat Redaksi/Penerbit:}

Jl. Negara No. 3 Candimas Kotabumi Lampung Utara

No Telpon/Fax 072423003

Email : 1ppm-stmik@dcc.ac.id 


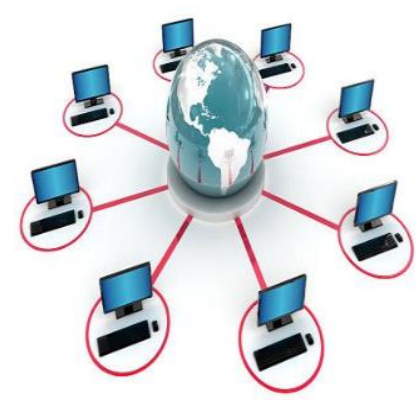

\section{JURNAL INFORMASI DAN KOMPUTER VOL. 9 NO. 2 THN. 2021}

\section{DAFTAR ISI}

Halaman

Sistem Informasi Akuntansi Persedian Barang Berbasis Web Pada Lembaga

Permasyarakatan Kelas II A Banceuy Bandung : "Kelompok Tani Desa Banjar Kertarahayu" Teuku Rian Hardiyansyah, Fatia Salsa Azzahra (Politeknik Piksi Ganesha Bandung ${ }^{1,2}$ )

Penerapan Finite State Automata Pada Vending Machine Penjual Obat Non Resep

Dokter Dan Keperluan Medis

Eko Supriyanto $^{1}$, Angga Ardiansyah ${ }^{2}$, Frieyadie $^{3}$, Sri Rahayu ${ }^{4}$, Windu Gata ${ }^{5}$

(Universitas Nusa Mandiri ${ }^{12}$ )

Sistem Pendukung Keputusan Untuk Menentukan Kelayakan Pengajuan Sertifikasi Guru Dengan Metode Simple Additive Weighting (Studi Kasus : Ma Al Muhajirin Janti Jogoroto Jombang)

Budiman, umam baharudin, winarti

(Universitas Darul 'Ulum Jombang)

Perancangan Infrastruktur Domain Name Server Lokal Menggunakan Ubuntu Server 16.04

Pada PT. Xyz

Zaenal Mutaqin Subekti, Hendra Setiawan, Satria, Widia Murni Wijaya,

Aliy Hafiz, Warsudi

(STMIK Bani Saleh, Universitas Negeri Yogyakarta, AMIK Dian Cipta Cendikia,

STMIK MIC CIkarang)

Perancangan Sistem Informasi Idea Proposal (Ip) Berbasis Web Pada Pt. Paxel Algorita Unggul

Julian Murhan Sahputra, Indah Purnamasari

(Universitas Nusa Mandiri ${ }^{12}$ )

Sistem Pendukung Keputusan Untuk Menentukan Ekstrakurikuler Atletik

Berdasarkan Bakat Siswa Menggunakan Metode Profile Matching

Agnes Basuki, Petrus Sokibi, Tiara Eka Putri

(Universitas Catur Insan Cendekia)

Penerapan Algoritma K-Means Untuk Pengelompokan Usia Calon Penerima Vaksin

Di Kab. Ngawi

Irna Yuniarfi, Saifulloh

(Universitas PGRI Madiun $^{12}$ )

System Penilaian Seleksi Calon Karyawan Baru Menggunakan Metode Simple Additive Weighting (SAW) Di PT.TNA

Anik Sri Wahyuningsih, Yudhi Firmansyah

(Universitas Panca Sakti Bekasi ) 
Perancangan Sistem Informasi Pembayaran SPP Menggunakan Framework Laravel Ichwan Habib Moudi

(Universitas Panca Sakti Bekasi)

Implementasi Algoritma K-Means Dan Algoritma Apriori Optimasi Kinerja Ecu

(Study Kasus Mobil Avanza Dan Xenia)

Sigit Mintoro' Asep Afandi

(STMIK Dian Cipta Cendikia Kotabumi)

Sistem Pakar Penyakit Buah Kakao Untuk Peningkatan Hasil Panen Kakao Menggunakan

Metode Case Base Reasoning (CBR) Berbasis Web Mobile

Aliy hafiz, Verawati

(AMIK Dian Cipta Cendikia,Bandar Lampung)

Penerapan Metode Rapid Application Develomment (RAD) Dalam Pengembangan

Sistem Pemesanan Menu Berbasis Android

Aris Baihaqi, Tumini

(Fakultas Sains dan Teknologi ${ }^{1,2}$ )

Rancang Bangun Sistem Informasi Geografis Pariwisata Di Lampung Timur

Sukatmi, Rexa Alfa Rizi

(AMIK DCC Bandar Lampung ${ }^{12}$ )

Implementasi Psak No. 45 Pada Proses Penyusunan Laporan Keuangan Menggunakan

M.S. Excel Dan Aplikasi Accurate Accouting Pada STMIK Bani Saleh

Marhakim, Willy Adam

(STMIK Bani Saleh ${ }^{12}$ )

Sistem Prediksi Harga KOPI LAMBAR ( Lampung Barat) Dengan Metode

Backpropagation, dan Double Exponential ( Studi Kasus BUMDES )

Supriyanto, Dwi marisa Efendi,Rhomadhon

(STMIK Dian Cipta cendikia Kotabumi ${ }^{1-}$ )

Sistem Informasi Pemasaran Produk Umkm Berbasis Web Pada Kecamatan Bumi

Nabung Lampung Tengah

Yuli Syafitri, Agus Prasetyo, Reni Astika

(AMIK Dian Cipta Cendikia Bandar Lampung)

Rancang Bangun Aplikasi Pembelajaran Aksara Lampung Berbasis Android

Ferly Ardhy, Hendra Syahrobi

(Universitas Aisyah Pringewu ${ }^{1,}$ STMIK Dian Cipta Cendikia ${ }^{2}$ )

Sistem Pakar Diagnosa Penyakit Kulit Pada Balita Menggunakan Metode Naïve

Bayes Dan Forward Chaining Studi Kasus Puskesmas Cempaka Sungkai Selatan

Sidik Rahmatullah, Rima Mawarni

(STMIK Dian Cipta Cendikia Kotabumi ${ }^{12}$ )

Rekayasa Perangkat Lunak Perhitungan Harga Pokok Produksi Metode

Full Costing Pada Umkm Mitra Cake Di Bandar Lampung

Pitrawati, Arif Sanjaya

(AMIK Dian Cipta Cendikia, Bandar Lampung) 
Rancang Bangun Sistem Ujian Online Menggunakan Algoritma Cosine Similarity

Berbasis Web

Haryono, Zaenal Mutaqin Subekti, Widiyawati, Hidayatullah

(STMIK Bani Saleh ${ }^{1234}$ )

Model Aplikasi Helpdesk Ticketing System Berbasis Web Menggunakan Metode Rad

Indra Permana

Pattern Recognition Tulisan Tangan Huruf Hijaiyah Menggunakan Metode

Convolutional Neural Network (CNN)

Mufassiril Abror, Nopiyanto

(Universitas Panca Sakti Bekasi ${ }^{12}$ )

Aplikasi Sistem Informasi Keuangan Berbasis Android Di Perumahan Taman

Karang Bahagia

Melda Ayulestari

(Universitas Panca Sakti Bekasi)

Audit Pelayanan Sistem Rujukan Online Puskesmas Menggunakan Framework COBIT 5.0

Nurmayanti, Merri Parida, Ngajiyanto, Ina Anzalna

(STMIK Dian Cipta Cendikia Kotabumi ${ }^{1234}$ )

Perancangan Sistem Informasi Pengolahan Data Nilai Siswa Berbasis Web

Erin Ermawati, Anik Sri Wahyuningsih

(Fakultas Sain dan Teknologi, Universitas Panca Sakti Bekasi ${ }^{12}$ )

Pengembangan Sistem Pelaporan Data Hasil Inspeksi Barang Berbasis Web

Siska Putriani

(Universitas Pancasakti Bekasi)

Penerapan Extreme Programming Dalam Perancangan Aplikasi Web Food Market

Tumini, Hilman Septiana

(Fakultas Sains dan Teknologi Universitas Panca Sakti Bekasi ${ }^{1,2}$ )

Sistem Pencarian Barang Berbasis Website Menggunakan Php Dan Mysq1

Studi Kasus PT. Surya Technology Industri Sulaeman

(Universitas Panca Sakti Bekasi)

Implementasi Metode Prototype Pada Sistem Peminjaman Alat Kerja Berbasis Web

Di PT SK Metalindo

Ali Mulyanto, Arjun Gunawan

(Univeritas Panca Sakti Bekasi)

Aplikasi Tata Cara Wudhu Menggunakan Teknologi Augmented Reality

Sebagai Media Pembelajaran Di TK Al Fatih

Ahmad Yakub , Idarul Fadli

(Universitas Panca Sakti Bekasi ${ }^{12}$ )

Sistem Pakar Diagnosa Penyakit Ayam Petelur Menggunakan Metode Certainty Factor

Berbasis Web Mochammad

Taufiq Hidayat, Ali Mulyanto

(Universitas Panca Sakti Bekasi ${ }^{12}$ ) 
Penerapan Metode Prototyping Dalam Perhitungan Hasil Produksi Menggunakan

Arduino Uno R3 Dan Php Di PT. Indonesia Epson Industry

Amandha Aulia, Ajar Rohmanu

(Universitas Panca Sakti Bekasi ${ }^{12}$ )

System Pendukung Keputusan Penentuan Guru Teladan Dengan Metode Profile Matching

Hasbulloh, Agmawarnida

(Universitas Panca Sakti Bekasi ${ }^{1,2}$ )

Implementasi Waterfall Method Pada Aplikasi Buku Induk Siswa Berbasis Web

Idam Holid, Yogie Krisnayadi

(Universitas Panca Sakti ${ }^{12}$ )

Pengembangan Text To Speech Media Pembelajaran Untuk Pengenalan

Anggota Tubuh Manusia Kelas V Sekolah Dasar

Juwanda Saputra, Ali Mulianto

(Teknik Infomratika Fakulutas Sains dan Teknologi ${ }^{12}$ )

Perancangan Sistem Peminjaman Barang Berupa Aset Tetap Berbasis Web

Pada Lembaga Permasyarakatan Kelas II A Banceuy Bandung

Guntur Salasa Priambodo, Perwito, Candra Mecca Sufyana

(Politeknik Piksi Ganesha Bandung ${ }^{1,2,3}$ )

Metode Pemilihan Karyawan Terbaik Sebagai Penentu Goodwill Perguruan Tinggi

Dengan Menggunakan Metode Topsis (Studi Kasus Perguruan Tinggi Di Lampung Utara)

Dwi Sartika, Pakarti Riswanto

(STMIK Dian Cipta Cendikia Kotabumi)

Sistem Pendukung Keputusan Pemilihan Merek Smartphone Menggunakan

Metode Analytical Hierarchy Process (AHP)

Ade Kiki Fatmawati, Muhammad Sultan Raflie, Norma Yunita

(Universitas Nusa Mandiri ${ }^{123}$ )

Pattern Recognition Aksara Lampung Menggunakan Algoritma Neural Network

Metode Analytical Hierarchy Process (AHP)

Nopiyanto, Rahmadi

(Universitas Panca Sakti Bekasi) 


\title{
SYSTEM PENILAIAN SELEKSI CALON KARYAWAN BARU MENGGUNAKAN METODE SIMPLE ADDITIVE WEIGHTING (SAW) DI PT.TNA
}

\author{
Anik Sri Wahyuningsih ${ }^{1}$, Yudhi Firmansyah ${ }^{2}$ \\ Universitas Panca Sakti Bekasi \\ Kampus C Jl. Kapten Sumantri No 16 Cikarang, kab. Bekasi 17530 \\ E-mail : anikstmik@gmail.com ${ }^{1}$, yudhifirmansyah80@ gmail.com²
}

\begin{abstract}
ABSTRAK
Dalam hal penerimaan karyawan baru atau rekrutmen adalah suatu keharusan dan hal yang penting bagi perusahaan untuk memperoleh calon karyawan baru dalam menduduki suatu jabatan dalam suatu pekerjaan. Banyak perusahaan dalam proses penerimaan karyawan baru masih belum dilakukan secara profesional. Hal ini terjadi karena tidak ada metode standar yang sistematis untuk menilai kelayakan calon karyawan baru. Biasanya dalam pengambilan keputusan penerimaan karyawan baru dilakukan secara manual dengan melihat semua data-data calon karyawan dan ini membutuhkan waktu yang lama. Dengan melihat fenomena tersebut peran divisi Sumber Daya Manusia (SDM) dalam menangani permasalahan penerimaan karyawan baru tentunya masih belum maksimal. Peran divisi Sumber Daya Manusia (SDM) dalam hal ini staff hingga manajer yang melakukan seleksi sangat dibutuhkan sejak awal proses penerimaan karyawan baru. Untuk memecahkan permasalahan tersebut perlu dibuatkan suatu sistem pendukung keputusan yang dapat membantu perusahaan terutama manajer divisi Sumber Daya Manusia (SDM) dalam pengambilan keputusan untuk menentukan karyawan baru di suatu perusahaan. Salah satu aplikasi sistem pendukung keputusan penerimaan karyawan baru yaitu menggunakan metode Simple Additive Weighting (SAW). Salah satu metode ini dipilih karena dapat menentukan nilai bobot untuk setiap atribut, kemudian dilanjutkan dengan proses perankingan yang akan menyeleksi alternatif terbaik dari sejumlah alternatif, dalam hal ini alternatif yang dimaksud adalah yang berhak dan layak diterima sebagai karyawan baru berdasarkan kriteria-kriteria yang telah ditentukan sebelumnya. Berdasarkan dari hasil pengujian, sistem yang dibuat dan diterapkan dapat mempermudah dan mempercepat proses penyeleksian penerimaan karyawan baru sehingga membantu manajer pada divisi Sumber Daya Manusia (SDM) dalam pengambilan keputusan untuk menentukan karyawan baru di suatu perusahaan.
\end{abstract}

Kata kunci : Sistem Pendukung Keputusan, Perekrutan, Simple Additive Weighting (SAW)

\section{ABSTRACTS}

In terms of acceptance of new employees or recruitment, it is a must and important thing for companies to obtain prospective new employees in occupying a position in a job. Many companies in the process of hiring new employees are still not done professionally. This is because there is no standardized, systematic method for assessing the eligibility of new recruits. Usually, the decision making of new employees is done manually by looking at all the data on prospective employees and this takes a long time. By looking at this phenomenon, the role of the Human Resources (HR) division in dealing with the problem of recruiting new employees is certainly not optimal. The role of the Human Resources (HR) division, in this case the staff to managers who make the selection, is very much needed from the beginning of the process of recruiting new employees. To solve these problems, it is necessary to make a decision support system that can help companies, especially managers of the Human Resources (HR) division in making decisions to determine new employees in a company. One application of a decision support system for hiring new employees is using the Simple Additive Weighting (SAW) method. One of these methods was chosen because it can determine the weight value for each attribute, then proceed with 
a ranking process that will select the best alternative from a number of alternatives, in this case the alternative in question is the one who is entitled and deserves to be accepted as a new employee based on predetermined criteria. previously. Based on the test results, the system created and implemented can simplify and speed up the process of selecting new employees so that it helps managers in the Human Resources (HR) division in making decisions to determine new employees in a company.

Key word: Decission Support System, recruitment, Simple Additive Weighting (SAW)

\section{PENDAhuluan}

Karyawan dalam suatu perusahaan merupakan aset yang berharga untuk mencapai tujuannya. Salah satu fokus utama Manajemen Sumber Daya Manusia (SDM) adalah memberikan kontribusi atas suksesnya perusahaan sebagai tugasnya. Agar produktifitas perusahaan dapat berjalan lancar, sangat diperlukan pegawai atau karyawan yang sesuai dengan prinsip "the right man in the right place" atau "Orang yang tepat di tempat yang tepat". Maka dari itu langkah awal yang menjadi kunci utama yaitu proses rekrutmen dan seleksi untuk merekrut karyawan sesuai dengan kebutuhannya. Salah satunya adalah proses seleksi yang merupakan serangkaian langkah kegiatan yang digunakan untuk memutuskan kandidat karyawan yang dapat ditempatkan secara tepat. Seringkali perusahaan mengalami kesulitan dalam menentukan kandidat yang tepat mengingat bahwa ada banyak kandidat yang tersedia tetapi sangat sedikit yang memiliki kualifikasi yang tepat dan memadai.

Bilamana perusahaan sudah mempunyai kriteria atau gambaran tentang hasil analisis pekerjaan dan rancangan pekerjaan yang sesuai dengan kebutuhan dan tujuan perusahaan, maka tugas departemen Sumber Daya Manusia (SDM) adalah mengisi posisi atau jabatan tersebut dengan sumber daya manusia yang sesuai dan berkualitas untuk pekerjaan itu melalui proses rekrutmen.

Kualitas sumber daya manusia yang akan digunakan perusahaan sangat tergantung pada bagaimana prosedur awal rekrutmen dan seleksi dilaksanakan sehingga aktifitas pelaksanaan rekrutmen dan seleksi calon karyawan merupakan tugas yang sangat penting, krusial, dan membutuhkan tanggung jawab yang besar.

Beberapa perusahaan dalam proses penerimaan karyawan baru masih belum dilakukan secara profesional. Hal ini terjadi karena tidak ada metode standar yang sistematis untuk menilai kelayakan calon karyawan baru. Biasanya dalam pengambilan keputusan penerimaan karyawan baru dilakukan secara manual dengan melihat semua data-data calon karyawan dan ini membutuhkan waktu yang lama dan berpotensi kurang tepat sasaran.

Dari fenomena di atas, peran divisi Sumber Daya Manusia (SDM) dalam menangani masalah penerimaan karyawan baru tentunya masih belum maksimal. Peran divisi Sumber Daya Manusia (SDM) dalam hal ini staff hingga manajer yang melakukan seleksi sangat dibutuhkan sejak awal proses penerimaan karyawan baru. Untuk memecahkan permasalahan tersebut perlu dibuatkan suatu sistem pendukung keputusan yang dapat membantu perusahaan terutama manajer divisi Sumber Daya Manusia (SDM) dalam pengambilan keputusan.

Metode yang digunakan untuk menentukan calon karyawan adalah metode SAW. Konsep dasar dari metode simple additive weighting (SAW) adalah mencari jumlah tertinggi dari rating kandidat karyawan. Metode simple additive weighting (SAW) membutuhkan proses matriks keputusan $(\mathrm{X})$ ke suatu skala yang dapat dibandingkan dengan semua rating yang ada, sehingga dalam penyelesaiannya diperlukan sebuah sistem pendukung berbagai kriteria calon pelamar. Menurut penulis metode ini cukup efektif dalam seleksi dan penentuan akhir calon karyawan yang akan diterima oleh perusahaan. Pembuatan aplikasi sistem pendukung keputusan yang bertujuan membantu dalam memberi kemudahan kepada user / HRD dalam memilih karyawan dengan sebuah aplikasi.

\section{Referensi Pustaka}

\subsection{Definisi Sistem}

Sistem adalah kumpulan orang yang saling bekerja sama dengan ketentuan-ketentuan aturan yang sistematis dan terstruktur untuk membentuk satu kesatuan yang melaksanakan 
suatu fungsi untuk mencapai tujuan. Sistem memiliki beberapa karakteristik atau sifat yang terdiri dari komponen sistem, batasan sistem, lingkungan luar sistem, penghubung sistem, masukan sistem, keluaran sistem, pengolahan sistem dan sasaran system [1].

\subsubsection{Metode Pengembangan Sistem}

Menurut Jeffrey L. Whitten (2004) kebanyakan organisasi memiliki proses pengembangan sistem (system development process) resmi yang terdiri dari satu set standar proses atau langkah-langkah yang mereka harapkan akan diikuti oleh semua proyek pengembangan sistem. Proses pengembangan sistem di kebanyakan organisasi mengikuti pendekatan pemecahan masalah (problem solving). Pendekatan tersebut biasanya terdiri dari beberapa langkah pemecahan masalah yang umum, yaitu:

1. Mengidentifikasi masalah.

2. Manganalisis dan memahami masalah.

3. Mengidentifikasi persyaratan dan solusi yang diharapkan.

4. Mengidentifikasi solusi alternatif dan memilih tindakan yang terbaik.

5. Mendesain solusi yang dipilih.

6. Mengimplementasikan solusi yang dipilih.

7. Mengevaluasi hasilnya. (Jika masalah tidak terpecahkan, kembalilah ke langkah 1 atau 2 seperlunya).

Langkah-langkah pemecahan masalah tersebut sesungguhnya merupakan bagian dari tahapantahapan proses pengembangan sistem dalam strategi waterfall seperti yang dikemukakan oleh Jeffery L. Whitten (2004) bahwa pengembangan sistem terbagi menjadi empat tahapan metode yaitu Permulaan sistem (system initiation), Analisis sistem (system analysis), Desain sistem (system design), dan Implementasi sistem (system implementation). [2]

\subsection{Definisi Sistem Penunjang Keputusan (SPK)}

Sistem pendukung keputusan diperkenalkan oleh G. Anthony Gorry dan Michael S. Scott Morton. Keduanya adalah professor dari MIT menulis artikel dalam jurnal yang berjudul "framework for Management Information System". Mereka mengembangkan kerangka pemikiran tentang pemanfaatan aplikasi komputer pada proses pengambilan keputusan bagi level manajemen. Berdasarkan kerangka ini dapat didefinisikan bahwa sistem pendukung keputusan ini berkaitan erat dengan sistem informasi atau model analisis yang dirancang untuk membantu para pengambil keputusan dan para professional agar mendapatkan informasi yang akurat. (Rahman, A.,dkk, 2008), DSS sebenarnya merupakan implementasi teori-teori pengambilan keputusan yang telah diperkenalkan oleh ilmuilmu seperti operation research dan management science. Hanya bedanya adalah bahwa jika dahulu untuk mencari penyelesaian masalah yang dihadapi harus dilakukan perhitungan iterasi secara manual (biasanya untuk mencari nilai minimum, maksimum, atau optimum), saat ini komputer PC telah menawarkan kemampuannya untuk menyelesaikan persoalan yang sama dalam waktu relatif singkat. Sistem pendukung keputusan memberikan dukungan kepada seorang manajer atau kepada sekelompok manajer dalam memecahkan masalah semi terstruktur dengan memberikan informasi atau saran mengenai keputusan tertentu, informasi tersebut dapat diberikan dalam bentuk laporan berkala, laporan khusus maupun model matematis. Model tersebut juga mempunyai kemampuan untuk memberikan saran dalam tingkat yang bervariasi. Sistem pendukung keputusan ini merupakan pengembangan dari sistem informasi manajemen dalam pengambilan keputusan yang difokuskan pada dukungan kepada manajemen. Keberadaan sistem pendukung keputusan ini bukan untuk menggantikan tugas-tugas manajer, tetapi untuk menjadi sarana pendukung bagi mereka. Sistem ini merepresentasikan permasalahan manajemen yang dihadapi sehari-hari ke dalam bentuk kuantitatif, misalnya dalam bentuk model matematika.

Pada awalnya, sistem pendukung keputusan dibangun untuk mendukung manajemen dalam pengambilan keputusan. Berbagai kebutuhan dalam pengembangan sistem pendukung keputusan adalah :

Data, informasi, basis data dan analisa modelmodel keputusan.

Data dan informasi yang akurat merupakan kebutuhan mendasar untuk mengambil keputusan, untuk hal ini, tahapan pengumpulan data dan informasi, pemrosesan data dan informasi lalu menggunakannya sebagai bahan 
pertimbangan dalam mengambil keputusan merupakan tahapan yang penting.

\section{a. Antar muka sistem}

Antar muka sistem haruslah mudah digunakan. Sistem pendukung keputusan harus dibangun dengan sederhana, memiliki daya tahan terhadap gangguan, mudah dikontrol, lengkap dan mudah digunakan agar sistem dapat benarbenar membantu manajer dalam mengambil keputusan. Hal ini sangat penting sekali karena kesalahan dalam pengambilan keputusan akan sangat besar pengaruhnya terhadap organisasi atau perusahaan.

\section{b. Dibangun untuk membantu pengambil keputusan.}

Penting untuk diingat bahwa sistem ini dibangun bukan untuk mengantikan posisi manusia sebagai pengambil keputusan. Sistem ini hanya membantu pengambil keputusan dengan menyediakan informasi yang lengkap dan akurat.

\section{c. Sistem ini dapat memberikan beberapa alternative solusi.}

Sistem pendukung keputusan diharapkan dapat memberikan berbagai alternative solusi. Penerapan suatu model diharpakan dapat memberikan perangkingan alternative dari yang terbaik sampai yang terburuk.

\section{d. Sistem ini menyediakan akses informasi dari berbagai sumber data dan berbagai format.}

Format informasi bisa dalam bentuk rekapitulasi, laporan perperiode waktu tertentu, grafik, histogram, ogive dan sebagainya. [3].

\subsubsection{Tujuan implementasi SPK}

Tujuan implementasi sistem pendukung keputusan antara lain :

1. Sistem pendukung keputusan berbasis komputer dapat memungkinkan mengambil keputusn dengan waktu yang cepat karena dengan dukungan sistem yang dapat memproses data secara cepat dengan jumlah banyak.

2. Sistem pendukung keputusan ditujukan untuk membantu dalam mengambil keputusan,bukan untuk manggantikan tugas seorang pengambil keputusan. Se- hingga dengan data dan informasi yang akurat diharapkan dapat membantu membuat keputusan yang berkualitas.

3. Mampu menghasilkan keputusan yang efektif (sesuai tujuan) dan efisien.

4. Meningkatkan kemampuan untuk mendeteksi adanya kesalahan pada suatu sistem sehingga dapat dilakukan antisipasi [4].

\subsubsection{Tahapan Pengambilan keputusan}

Untuk menghasilkan keputusan yang baik ada beberapa tahapan proses yang harus dilalui dalam pengambilan keputusan.

Menurut Julius Hermawan (2002:3), proses pengambilan keputusan melalui beberapa tahap berikut :

\section{a. Tahap Penelusuran(intelligence)}

Tahap ini pengambil keputusan mempelajari kenyataan yang terjadi, sehingga kita bisa mengidentifikasi masalah yang terjadi biasanya dilakukan analisis dari sistem ke subsistem pembentuknya sehingga didapatkan keluaran berupa dokumen pernyataan masalah.

\section{b. Tahap Desain}

Dalam tahap ini pengambil keputusan menemukan, mengembangkan dan menganalisis semua pemecahan yang mungkin yaitu melalui pembuatan model yang bisa mewakili kondisi nyata masalah. Dari tahapan ini didapatkan keluaran berupa dokumen alternatif solusi.

\section{c. Tahap Choice}

Dalam tahap ini pengambil keputusan memilih salah satu alternatif pemecahan yang dibuat pada tahap desain yang dipandang sebagai aksi yang paling tepat untuk mengatasi masalah yang sedang dihadapi. Dari tahap ini didapatkan dokumen solusi dan rencana implementasinya.

\section{d. Tahap Implementasi}

Pengambil keputusan menjalankan rangkaian aksi pemecahan yang dipilih di tahap choice. Implementasi yang sukses ditandai dengan terjawabnya masalah yang dihadapi, sementara 
kegagalan ditandai masih adanya masalah yang sedang dicoba untuk diatasi. Dari tahap ini didapatkan laporan pelaksanaan solusi dan hasilnya [5].

\subsection{Definisi Basis Data}

Basis data (database) dalam dunia komputer, terutama oleh pemrogram (programmer) sudah tidak asing lagi karena seringkali disinggung dan berhubungan langsung. Namun untuk memudahkan memahami apa yang dimaksud dengan basis data, ada baiknya dibahas terlebih dahulu apa yang dimaksud dengan basis data.

Basis data merupakan gabungan file data yang dibentuk dengan hubungan/relasi yang logis dan dapat diungkapkan dengan catatan serta bersifat independen. Adapun basis data adalah:

"Tempat berkumpulnya data yang saling berhubungan dalam suatu wadah (organisasi/perusahaan) bertujuan agar dapat mempermudah dan mempercepat untuk pemanggilan atau pemanfaatan kembali data tersebut."

Arti lain dari sistem basis data adalah :

"Suatu sistem penyusunan dan pengelolaan record-record dengan menggunakan komputer, dengan tujuan untuk menyimpan atau merekam serta memelihara data secara lengkap pada sebuah organisasi /perusahaan, sehingga mampu menyediakan informasi yang optimal yang diperlukan pemakai untuk kepentingan proses pengambilan keputusan." [6]

\subsection{LARAVEL}

Laravel adalah salah satu web application Framework yang bersifat opensource. Framework ini berjalan di atas PHP5 dan berbasis MVC (Model Vie Controller). Laravel pertama kali dirilis pada 22 Februari 2012, dan versi stabil terbaru adalah versi 4.2.11 yang dirilis pada 4 Oktober 2014 [7].

\subsection{MySQL dan XAMPP}

\section{MySQL}

MySQL adalah sebuah implementasi dari sistem manajemen basisdata relasional (RDBMS) yang didistribusikan secara gratis dibawah lisensi GPL (General Public License). Setiap pengguna dapat secara bebas menggunakan MySQL, namun dengan batasan perangkat lunak tersebut tidak boleh dijadikan produk turunan yang bersifat komersial. MySQL sebenarnya merupakan turunan salah satu konsep utama dalam basisdata yang telah ada sebelumnya; SQL (Structured Query Language). SQL adalah sebuah konsep pengoperasian basisdata, terutama untuk pemilihan atau seleksi dan pemasukan data, yang memungkinkan pengoperasian data dikerjakan dengan mudah secara otomatis.

Kehandalan suatu sistem basisdata (DBMS) dapat diketahui dari cara kerja pengoptimasinya dalam melakukan proses perintah-perintah SQL yang dibuat oleh pengguna maupun programprogram aplikasi yang memanfaatkannya. Sebagai peladen basis data, MySQL mendukung operasi basisdata transaksional maupun operasi basisdata nontransaksional. Pada modus operasi nontransaksional, MySQL dapat dikatakan unggul dalam hal unjuk kerja dibandingkan perangkat lunak peladen basisdata kompetitor lainnya.

\section{XAMPP}

XAMPP adalah sebuah software web server apache yang didalamnya sudah tersedia database server MySQL dan dapat mendukung pemrograman PHP. XAMPP merupakan software yang mudah digunakan, gratis dan mendukung instalasi di Linux dan Windows. Keuntungan lainnya adalah cuma menginstal satu kali sudah tersedia Apache Web Server, MySQL Database Server, PHP Support (PHP 4 dan PHP 5) dan beberapa module lainnya [8].

\subsection{Definisi Metode Simple Additive \\ Weighting (SAW)}

Metode SAW (Simple Additive Weighting) merupakan suatu metode yang digunakan untuk mencari alternatif optimal dari sejumlah alternatif dengan kriteria tertentu. Inti dari SAW adalah menentukan nilai bobot untuk setiap atribut, kemudian dilanjutkan dengan proses perankingan yang akan menyeleksi alternatif yang sudah diberikan. Pada dasarnya, ada 3 pendekatan untuk mencari nilai bobot atribut, yaitu pendekatan subyektif, pendekatan obyektif dan pendekatan integrasi antara subyektif \& obyektif. Masing-masing pendekatan memiliki kelebihan dan kelemahan. Pada pendekatan subyektif, nilai bobot ditentukan berdasarkan subyektifitas dari para pengambil keputusan, 
sehingga beberapa faktor dalam proses perankingan alternatif bisa ditentukan secara bebas. Sedangkan pada pendekatan obyektif, nilai bobot dihitung secara matematis sehingga mengabaikan subyektifitas dari pengambil keputusan.

Langkah-langkah Penyelesaian Metode SAW Langkah penyelesaian dalam menggunakan metode SAW adalah sebagai berikut :

1. Menentukan alternatif (kandidat)

2. Menentukan kriteria yang akan dijadikan acuan dalam pengambilan keputusan

3. Memberikan nilai rating kecocokan setiap alternatif pada setiap kriteria.

4. Menentukan bobot preferensi atau tingkat kepentingan untuk setiap kriteria.

5. Membuat tabel rating kecocokan dari setiap alternatif pada setiap kriteria.

6. Membuat matrik keputusan X yang dibentuk dari tabel rating kecocokan dari setiap alternatif pada setiap kriteria. Nilai X setiap alternatif pada setiap kriteria yang sudah ditentukan.

7. Melakukan normalisasi matrik keputusan $\mathrm{X}$ dengan cara menghitung nilai rating kinerja ternomalisasi dari alternatif Ai pada kriteria $\mathrm{Cj}$ dengan melakukan pengelompokan, apakah $\mathrm{j}$ adalah kriteria keuntungan (benefit) atau $\mathrm{j}$ adalah kriteria biaya (cost), maksudnya adalah:

a. Dikatakan kriteria keuntungan apabila nilai xij memberikan keuntungan bagi pengambil keputusan, sebaliknya kriteria biaya apabila xij menimbulkan biaya bagi pengambil keputusan.

b. Apabila berupa kriteria keuntungan maka nilai xij dibagi dengan nilai Max,i(xij) dari setiap kolom, sedangkan untuk kriteria biaya, nilai Min, i(xij)dari setiap kolom dibagi dengan nilai xij.

8. Hasil dari nilai rating kinerja ternomalisasi (rij) membentuk matrik ternormalisasi.

9. Hasil akhir nilai preferensi diperoleh dari penjumlahan untuk setiap perkalian elemen baris matrik ternormalisasi (R) dengan bobot preferensi (W) yang bersesuaian eleman kolom matrik (W). Hasil perhitungan nilai Vi yang lebih besar mengindikasikan bahwa alternatif Ai merupakan alternatif terbaik.

10. Menentukan Nilai Indikasi.

11. Perangkingan. Perangkingan dilakukan dengan cara mengalikan nilai SAW dengan nilai Indikasi dan hasil akhir dari nilai akan di rangking sesuai urutan hasil yang mempunyai nilai paling besar sampai yang terkecil [9].

Metode Simple Additive Weighting (SAW) merupakan salah satu metode penyelesaian masalah. Yang sering juga dikenal dengan istilah metode penjumlahan berbobot. Konsep dasar metode SAW adalah mencari penjumlahan terbobot dari rating kinerja pada setiap alternatif dari semua atribut (Fishburn, 1967). Metode SAW membutuhkan proses normalisasi matriks keputusan (x) ke suatu skala yang dapat diperbandingkan dengan semua rating alternatif yang ada [10].

Adapun langkah-langkah penyelesaiannya adalah sebagai berikut:

1. Menentukan alternatif, yaitu $\mathrm{A}_{\mathrm{i}}$,

2. Menentukan kriteria yang akan dijadikan acuan dalam pengambilan keputusan, yaitu $\mathrm{C}_{\mathrm{j}}$

3. Menentukan bobot preferensi atau tingkat kepentingan (W) setiap kriteria. $\mathrm{W}=\left[\mathrm{W}_{1}, \mathrm{~W}_{2}, \mathrm{~W}_{3}, \ldots . \mathrm{W}_{\mathrm{j}}\right]$

4. Membuat tabel rating kecocokan dari setiap alternatif pada setiap kriteria.

5. Membuat matriks keputusan (x) yang dibentuk dari tabel rating kecocokan dari setiap alternatif pada setiap kriteria. Nilai $\mathrm{x}$ setiap alternatif $\left(\mathrm{A}_{\mathrm{i}}\right)$ pada setiap kriteria $\left(C_{j}\right)$ yang sudah ditentukan, di mana, $\mathrm{i}=1,2, \ldots \mathrm{m}$ dan $\mathrm{j}=1,2, \ldots \mathrm{n}$

$$
\mathrm{X}=\left[\begin{array}{lllc}
x_{11} & x_{12} & \ldots & x_{1 j} \\
\cdot & & & \cdot \\
\dot{x}_{i 1} & x_{i 2} & \ldots & x_{i j}
\end{array}\right]
$$

6. Melakukan normalisasi matrik keputusan dengan cara menghitung nilai rating kinerja ternomalisasi $\left(r_{i j}\right)$ dari alternatif $A_{i}$ pada kriteria $\mathrm{C}_{\mathrm{j}}$.

$$
\begin{aligned}
r_{i j}= & \left\{\left[\begin{array}{lr}
\frac{x_{i j}}{\max _{i} x_{i j}} & \text { jika } j \text { adalah atribut keuntungan }(\text { benef } i t) \\
\frac{\min _{i} x_{i j}}{x_{i j}} & \text { jika } j \text { adalah atribut biaya }(\text { cost })
\end{array}\right]\right. \\
\text { (1) } &
\end{aligned}
$$

Keterangan:
a. Kriteria keuntungan dilakukan apabila nilai memberikan keuntungan bagi pengambil 
keputusan. Tetapi sebaliknya, kriteria biaya dilakukan apabila menimbulkan biaya bagi pengambil keputusan.

b. Apabila berupa kriteria keuntungan maka nilai dibagi dengan nilai dari setiap kolom. Sedangkan untuk kriteria biaya, nilai dari setiap kolom dibagi dengan nilai.

7. Hasil dari nilai rating kinerja ternomalisasi $\left(\mathrm{r}_{\mathrm{ij}}\right)$ membentuk matris ternormalisasi $(\mathrm{R})$.

$$
\mathrm{R}=\left[\begin{array}{lllr}
r_{11} & r_{12} & \ldots & r_{1 j} \\
\cdot & & & \cdot \\
r_{i 1} & r_{i 2} & \ldots & r_{i j}
\end{array}\right]
$$

8. Hasil akhir nilai preferensi $\left(\mathrm{V}_{\mathrm{i}}\right)$ diperoleh dari penjumlahan dan perkalian elemen baris matrik ternormalisasi (R) dengan bobot preferensi (W) yang bersesuaian elemen kolom matrik (W).

$$
V_{i}=\sum_{j=1}^{n} W_{j} r_{i j}
$$

Keterangan :

$\mathrm{V}_{\mathrm{i}}=$ Nilai bobot preferensi dari setiap alternatif

$\mathrm{W}_{\mathrm{j}}=$ Nilai bobot dari setiap kriteria

$\mathrm{R}_{\mathrm{ij}}=$ Nilai rating kinerja ternormalisasi

Hasil perhitungan nilai $\mathrm{V}_{\mathrm{i}}$ yang lebih besar mengindikasikan bahwa alternatif $\mathrm{A}_{\mathrm{i}}$ merupakan alternatif terbaik.

\section{HASIL DAN PEMBAHASAN}

\subsection{Metode pengumpulan Data}

Adalah suatu kegiatan untuk mendapatkan informasi dan data yang diperlukan dalam pengumpulan data yang berhubungan dengan penelitian dan pembuatan sistem yang berfungsi untuk mendukung penelitian diantaranya adalah sebagai berikut :

\subsubsection{Observasi /Pengamatan}

Penelitian yang dilakukan oleh penulis secara langsung pada objek atau subjek penelitian dengan atau tanpa menggunakan respon dari subjek yang diteliti, dengan tujuan untuk memperoleh data-data dari perusahaan pada bagian departemen yang terkait dengan mengadakan pengamatan secara langsung ke lokasi yang diamati. Penulis melakukan observasi pada PT. TNA yang berada di Jalan Surya Madya VI Kav. I-46 BC, Kutanegara, Kec. Ciampel, Kabupaten Karawang, Jawa Barat 41363.

\subsubsection{Wawancara/Interview}

Selain menggunakan metode observasi, penulis juga menggunakan metode interview atau wawancara, yaitu dengan cara menanyakan langsung kepada narasumber dalam hal ini dari bagian manajer HRD yakni ibu. Anis untuk mengetahui kondisi proses seleksi maupun penentuan terhadap calon karyawan yang selama ini telah dilakukan. Selain itu penulis juga melakukan wawancara kepada pihak-pihak terkait dengan cara berkomunikasi secara langsung untuk mengetahui informasi-informasi yang dibutuhkan seperti kriteria-kriteria maupun bobot yang harus dipenuhi oleh setiap calon pelamar agar dapat diterima oleh perusahaan.

\subsubsection{Studi Pustaka/Library Research}

Salah satu usaha yang dilakukan oleh penulis untuk mendapatkan informasi yang relevan dengan topik dan masalah yang akan dijadikan bahan penelitian. Informasi itu didapat dan diperoleh dari buku-buku ilmiah, laporan penilitian, jurnal, sumber-sumber tertulis baik tercetak maupun elektronik yang berhubungan dengan permasalahan yang berkaitan dengan sistem pendukung keputusan untuk penentuan calon karyawan terbaik menggunakan metode Simple Additive Weighting (SAW).

\subsection{Kerangka Pemikiran}

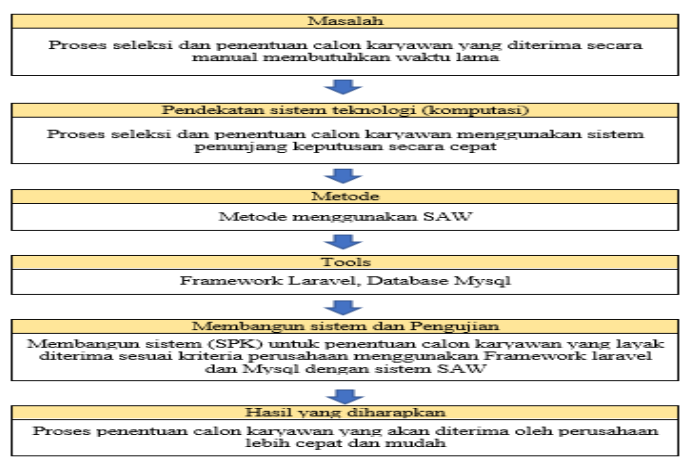

Gambar 1. Kerangka Pemikiran

\subsection{Kerangka penelitian}




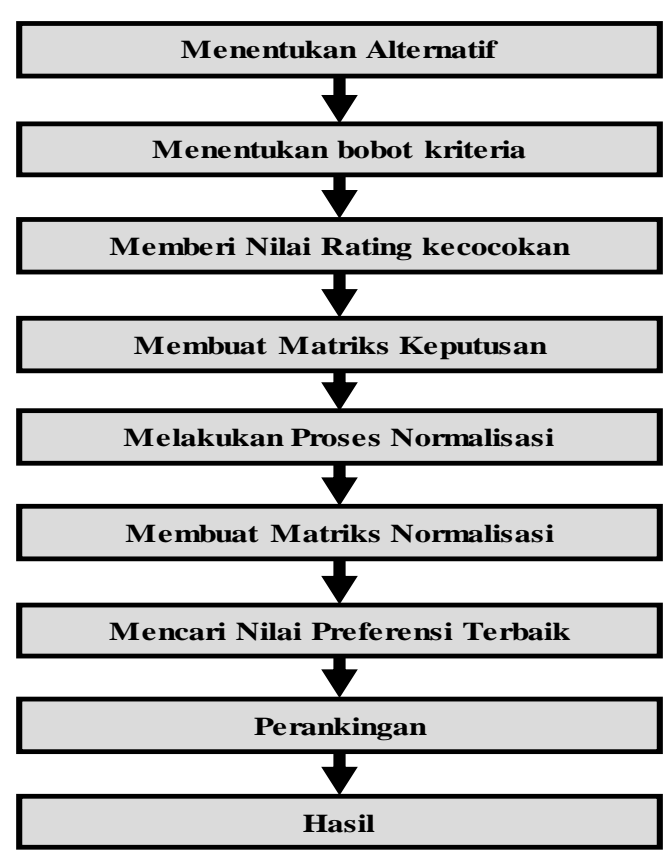

Gambar 2. Kerangka penelitian

\subsection{Hasil Penelitian}

\subsubsection{Menentukan Alternatif}

Terdapat alternatif kandidat atau calon karyawan yang dinilai dan ditandai dengan $A_{1}$ sampai $\mathrm{A}_{5}$ dengan uraian sebagai berikut:

Tabel 1. Data Alternatif

\begin{tabular}{|l|l|}
\hline$A_{i}$ & Nama \\
\hline$A_{1}$ & Andri Wahyudin \\
\hline$A_{2}$ & Irwan \\
\hline$A_{3}$ & Budi Susanto \\
\hline$A_{4}$ & Jaka \\
\hline$A_{5}$ & Kurniawan \\
\hline
\end{tabular}

\subsubsection{Penentuan Kriteria dan Bobot}

Dalam menentukan kriteria calon karyawan baru terdapat beberapa kriteria maupun bobot dari perusahaan yang harus dipenuhi calon pelamar yang telah disesuaikan dengan kondisi dan jenis pekerjaannya. Adapun kriteria maupun dalam penelitian ini adalah:

Tabel 2. Data Kriteria

\begin{tabular}{|l|l|l|l|}
\hline No & Kriteria $\left(\mathrm{C}_{\mathrm{j}}\right)$ & Bobot & $\begin{array}{c}\text { Nilai } \\
\text { Bobot }\end{array}$ \\
\hline
\end{tabular}

\begin{tabular}{|c|c|c|c|c|}
\hline & & & & (W) \\
\hline 1 & $\mathrm{C}_{1}$ & Wawancara & $15 \%$ & 0,15 \\
\hline 2 & $\mathrm{C}_{2}$ & Ujian Tulis & $20 \%$ & 0,20 \\
\hline 3 & $\mathrm{C}_{3}$ & Test Fisik & $30 \%$ & 0,30 \\
\hline 4 & $\mathrm{C}_{4}$ & $\begin{array}{l}\text { Nilai Sekolah } \\
\text { Matematika }\end{array}$ & $35 \%$ & 0,35 \\
\hline \multicolumn{4}{|c|}{ Bobot } & 1 \\
\hline
\end{tabular}

Tabel 3. Bobot Preferensi

\begin{tabular}{|l|c|}
\hline Kriteria Bobot & $\begin{array}{c}\text { Nilai Bobot Preferensi } \\
(\mathrm{W})\end{array}$ \\
\hline Rendah & 0,35 \\
\hline Sedang & 0,30 \\
\hline Tinggi & 0,20 \\
\hline Sangat Tinggi & 0,15 \\
\hline
\end{tabular}

\subsubsection{Memberi Nilai Rating Kecocokan}

Setiap alternatif untuk semua kriteria sebagai berikut:

Tabel 4. Data Alternatif Calon Karyawan

\begin{tabular}{|c|c|c|c|c|}
\hline \multirow{2}{*}{ Alternatif } & \multicolumn{4}{|c|}{ Kriteria } \\
\cline { 2 - 5 } & $\begin{array}{c}\text { Wawan } \\
\text { cara }\end{array}$ & $\begin{array}{c}\text { Ujia } \\
\mathrm{n} \\
\text { Tulis }\end{array}$ & $\begin{array}{c}\text { Test } \\
\text { Fisi } \\
\mathrm{k}\end{array}$ & $\begin{array}{c}\text { Nilai } \\
\text { Sekolah } \\
\text { Matema } \\
\text { tika }\end{array}$ \\
\hline $\begin{array}{c}\text { Andri } \\
\text { Wahyudi } \\
\mathrm{n}\end{array}$ & 75 & 85 & 70 & 80 \\
\hline $\begin{array}{c}\text { Irwan } \\
\text { Budi } \\
\text { Susanto }\end{array}$ & 70 & 90 & 80 & 80 \\
\hline Jaka & 85 & 85 & 80 & 85 \\
\hline $\begin{array}{c}\text { Kurniawa } \\
\mathrm{n}\end{array}$ & 90 & 85 & 85 & 90 \\
\hline
\end{tabular}

\subsubsection{Perhitungan Metode SAW}

\subsubsection{Membuat Matriks Keputusan}

Dari tabel alternatif pada tabel 2 maka dapat dibentuklah sebuah matriks keputusan $\mathrm{X}$ sebagai berikut:

$$
X=\left[\begin{array}{llll}
75 & 85 & 70 & 80 \\
80 & 90 & 80 & 80 \\
70 & 80 & 90 & 80 \\
85 & 85 & 80 & 85 \\
90 & 85 & 85 & 90
\end{array}\right]
$$




\subsubsection{Melakukan Proses Normalisasi}

Setelah bobot alternatif telah disesuaikan dengan nilai kecocokan maka masuk ke tahap normalisasi menggunakan rumus Persamaan (1) sebagai berikut:

$$
\begin{aligned}
& r_{11}=\frac{75}{\max \{75 ; 80 ; 70 ; 85 ; 90\}}=\frac{75}{90}=0,833 \\
& r_{12}=\frac{80}{\max \{75 ; 80 ; 70 ; 85 ; 90\}}=\frac{80}{90}=0,889 \\
& r_{13}=\frac{70}{\max \{75 ; 80 ; 70 ; 85 ; 90\}}=\frac{70}{90}=0,778 \\
& r_{14}=\frac{85}{\max \{75 ; 80 ; 70 ; 85 ; 90\}}=\frac{85}{90}=0,944 \\
& r_{15}=\frac{90}{\max \{75 ; 80 ; 70 ; 85 ; 90\}}=\frac{90}{90}= \\
& r_{21}=\frac{85}{\max \{85 ; 90 ; 80 ; 85 ; 85\}}=\frac{85}{90}=0,944 \\
& r_{22}=\frac{90}{\max \{85 ; 90 ; 80 ; 85 ; 85\}}=\frac{90}{90}=1 \\
& r_{23}=\frac{80}{\max \{85 ; 90 ; 80 ; 85 ; 85\}}=\frac{80}{90}=0,889 \\
& r_{24}=\frac{85}{\max \{85 ; 90 ; 80 ; 85 ; 85\}}=\frac{85}{90}=0,944 \\
& r_{25}=\frac{85}{\max \{85 ; 90 ; 80 ; 85 ; 85\}}=\frac{85}{90}=0,944 \\
& r_{31}=\frac{70}{\max \{70 ; 80 ; 90 ; 80 ; 85\}}=\frac{70}{90}=0,778 \\
& r_{32}=\frac{80}{\max \{70 ; 80 ; 90 ; 80 ; 85\}}=\frac{80}{90}=0,889 \\
& r_{33}=\frac{90}{\max \{70 ; 80 ; 90 ; 80 ; 85\}}=\frac{90}{90}=1 \\
& r_{34}=\frac{80}{\max \{70 ; 80 ; 90 ; 80 ; 85\}}=\frac{80}{90}=0,889 \\
& r_{35}=\frac{85}{\max \{70 ; 80 ; 90 ; 80 ; 85\}}=\frac{85}{90}=0,944 \\
& r_{41}=\frac{80}{\max \{80 ; 80 ; 80 ; 85 ; 90\}}=\frac{80}{90}=0,889 \\
& r_{42}=\frac{80}{\max \{80 ; 80 ; 80 ; 85 ; 90\}}=\frac{80}{90}=0,889
\end{aligned}
$$

$$
\begin{gathered}
r_{43}=\frac{80}{\max \{80 ; 80 ; 80 ; 85 ; 90\}}=\frac{80}{90} \\
=0,889 \\
r_{44}=\frac{85}{\max \{80 ; 80 ; 80 ; 85 ; 90\}}=\frac{85}{90} \\
=0,994 \\
r_{45}=\frac{90}{\max \{80 ; 80 ; 80 ; 85 ; 90\}}=\frac{90}{90} \\
=\quad 1
\end{gathered}
$$

\subsubsection{Membentuk Matriks Normalisasi (R)}

$$
R=\left[\begin{array}{cccc}
0,833 & 0,944 & 0,778 & 0,889 \\
0,889 & 1 & 0,889 & 0,889 \\
0,778 & 0,889 & 1 & 0,889 \\
0,944 & 0,944 & 0,889 & 0,944 \\
1 & 0,944 & 0,944 & 1
\end{array}\right]
$$

\subsubsection{Hasil akhir nilai preferensi}

Hasil akhir nilai preferensi (Vi) diperoleh dari penjumlahan dari perkalian elemen baris matrik ternormalisasi (R) dengan bobot preferensi (W) yang bersesuaian elemen kolom matrik (W) sesuai dengan rumus persamaan (2).

$$
\begin{aligned}
\mathrm{V}_{1}= & \{(0,15)(0,833)+(0,20)(0,944)+(0,30)( \\
& 0,778)+(0,35)(0,889)\} \\
& \{0,125+0,189+0,233+0,311\}=0,858 \\
\mathrm{~V}_{2}= & (0,15)(0,889)+(0,20)(1)+(0,30)( \\
& 0,889)+(0,35)(0,889)\} \\
& \{0,133+0,2+0,266+0,311\}=0,911 \\
\mathrm{~V}_{3}= & \{(0,15)(0,778)+(0,20)(0,889)+ \\
& (0,30)(1)+(0,35)(0,889)\} \\
& \{0,116+0,178+0,3+0,311\}=0,905 \\
\mathrm{~V}_{4}= & \{(0,15)(0,944)+(0,20)(0,944)+(0,30)( \\
& 0,889)+(0,35)(0,944)\} \\
& \{0,141+0,189+0,267+0,330\}=0,927 \\
\mathrm{~V}_{5}= & \{(0,15)(1)+(0,20)(0,944)+(0,30)(0,944) \\
& +(0,35)(1)\} \\
& \{0,15+0,189+0,283+0,35\}=0,972
\end{aligned}
$$

\subsubsection{Hasil Akhir Perankingan}

Hasil akhir perankingan calon karyawan dengan nilai tertinggi

Table 5. Hasil Perankingan

\begin{tabular}{|c|l|l|l|}
\hline Ranking & $\mathrm{V}_{\mathrm{i}}$ & \multicolumn{1}{|c|}{ Nama } & Nilai \\
\hline 1 & $\mathrm{~V}_{5}$ & Kurniawan & 0,971 \\
\hline 2 & $\mathrm{~V}_{4}$ & Jaka & 0,925 \\
\hline 3 & $\mathrm{~V}_{2}$ & Irwan & 0,911 \\
\hline 4 & $\mathrm{~V}_{3}$ & $\begin{array}{l}\text { Budi } \\
\text { Susanto }\end{array}$ & 0,904 \\
\hline 5 & $\mathrm{~V}_{1}$ & $\begin{array}{l}\text { Andri } \\
\text { Wahyudin }\end{array}$ & 0,858 \\
\hline
\end{tabular}

\subsection{Implementasi}

3.5.1 Form Frontend Untuk Calon Karyawan 
Form ini digunakan untuk mengisi biodata maupun hasil tes oleh pihak pelamar maupun penyalur tenaga kerja.

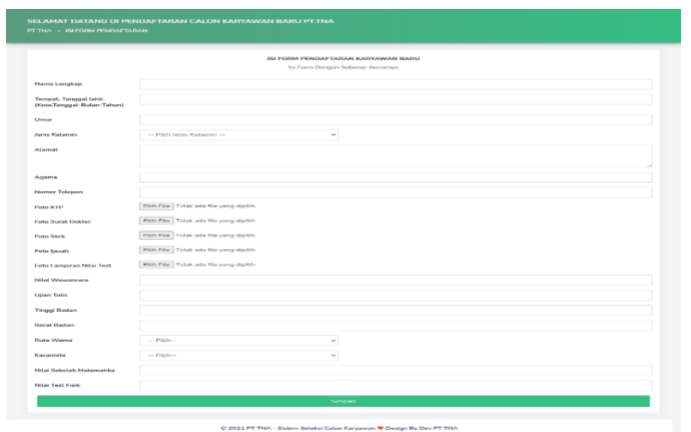

Gambar 3. Form Frontend Untuk Calon Karyawan

\subsubsection{Form Login}

Form ini digunakan admin atau staff HRD perusahaan untuk proses Login ke dalam aplikasi dengan input email dan password.

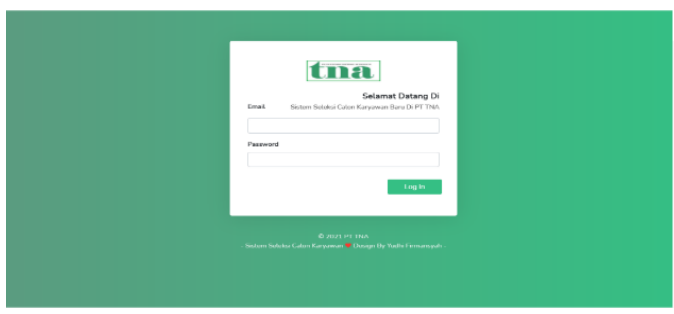

Gambar 4. Form Login

\subsubsection{Form Dashboard}

Tampilan form berikutnya adalah dashboard untuk mengetahui jumlah pelamar dari jenis pria maupun Wanita.

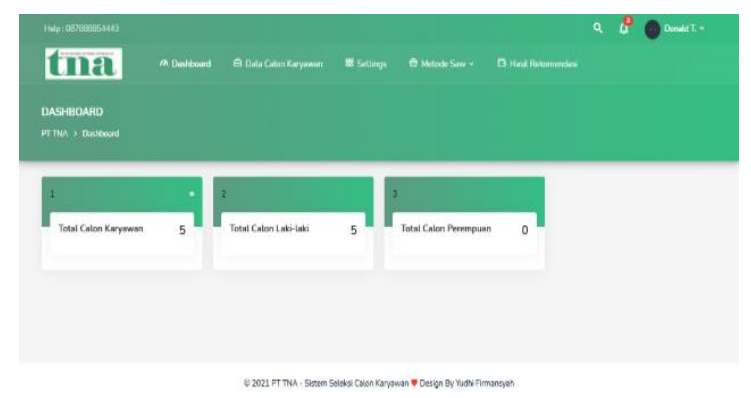

Gambar 5. Form Dashboard

\subsubsection{Form Calon Karyawan}

Form berikut ini menampilkan biodata semua pelamar yang sudah diisi.

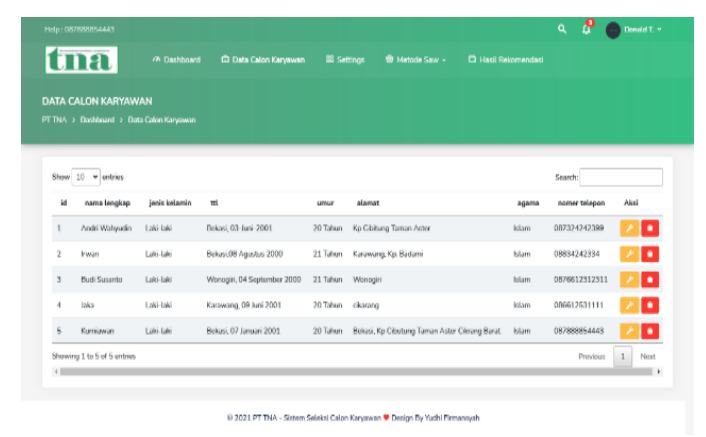

Gambar 6. Form Calon Karyawan

\subsubsection{Form Setting Bobot}

Form ini digunakan untuk menentukan bobot dari tiap-tiap kriteria penilaian.

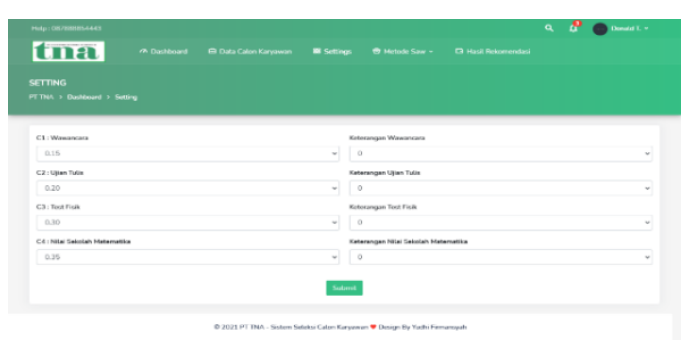

Gambar 7. Form Setting Bobot

\subsubsection{Form Matrix Nilai}

Form ini menampilkan semua hasil penilaian tiap-tiap kriteria dari semua calon pelamar yang berupa tabel matrik.

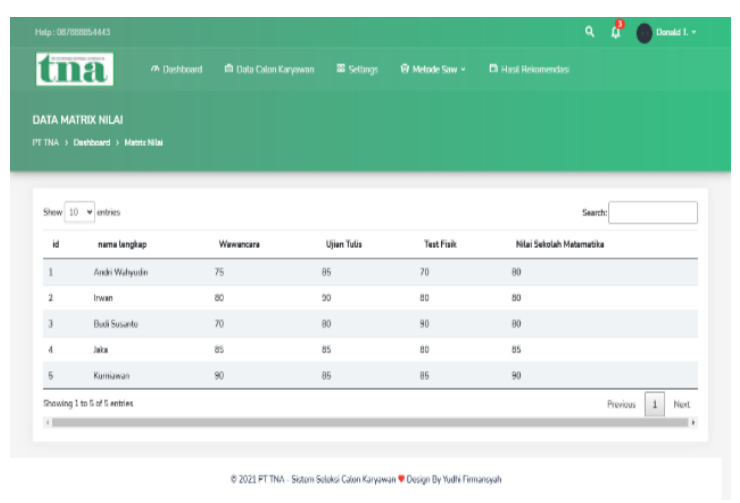

Gambar 8. Form Matrix Nilai 3.5.7 Form Normalisasi 
Form berikutnya adalah tampilan hasil normalisasi dari semua penilaian.

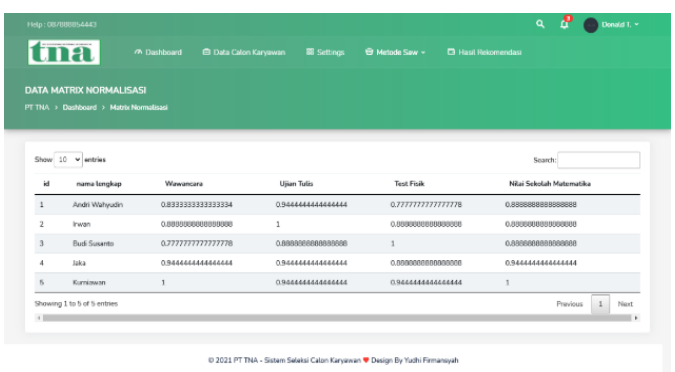

Gambar 9. Form Normalisasi

\subsubsection{Form Preferensi}

Di dalam form ini, semua hasil nilai normalisasi akan diproses penghitungan lagi menghasilkan data preferensi dari tiap-tiap calon pelamar.

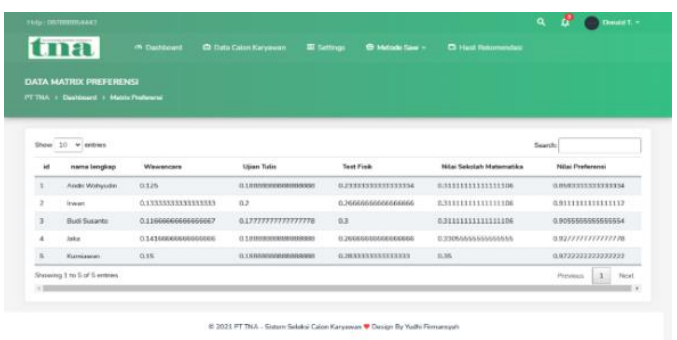

Gambar 10. Form Preferensi

\subsubsection{Form Hasil Rekomendasi}

Form ini menampilkan hasil perankingan dari semua nilai preferensi sehingga didapatkan urutan perankingan data pelamar yang terbaik berada paling atas untuk merekomendasikan kepada pihak pengambil keputusan dalam menentukan calon pelamar yang akan diterima perusahaan.

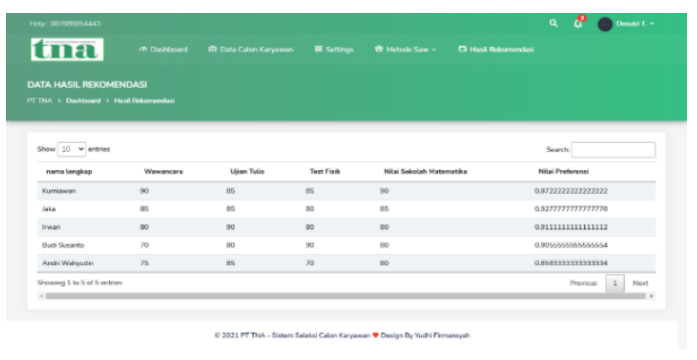

Gambar 11. Form Hasil Rekomendasi
Dari hasil proses penelitian yang dilakukan, maka penulis dapat menarik beberapa kesimpulan sebagai berikut:

1. Penerapan metode SAW digunakan untuk sistem seleksi dan penentuan calon karyawan perusahaan terbaik telah dilakukan sesuai dengan yang diharapkan.

2. Aplikasi ini sangat memudahkan staff HRD dalam menyeleksi calon karyawan dengan mengurutkan perankingan berdasarkan nilai bobot masing masing pelamar sehingga memudahkan pula menentukan calon karyawan yang dapat diterima.

3. Proses seleksi dan penentuan calon karyawan yang akan diterima perusahaan dapat dilakukan dengan lebih cepat.

\section{DAFTAR PUSTAKA}

[1] Elisabet Yunaeti Anggraeni, R. (2017). Pengantar Sistem Informasi. Yogyakarta: CV ANDI OFFSET.

[2] Nia Kumaladewi, Zulfiandri, \& Dicky Triyana. (2014). Pengembangan Sistem Informasi Pendaftaran Telkomflexi Classy (Studi Kasus: Kantor Daerah Telekomunikasi Jakarta Selatan). JURNAL SISTEM INFORMASI Fakultas Sains dan Teknologi UIN Syarif Hidayatullah - Jakarta Vol. 7 No. 2, Oktober 2014 ISSN: 1979 0767, 2.

[3] Diana, S.Si., M.Kom. (2018). Metode dan aplikasi Sistem Pendukung Keputusan. Yogyakarta: CV BUDI UTAMA.

[4] M. Harry K Saputra, \& Lusia Violita Aprilian. (2020). Belajar Cepat Metode $S A W$. Bandung: Kreatif Industri Nusantara.

[5] Sri Eniyati. (2011). Perancangan Sistem Pendukung Pengambilan Keputusan untuk Penerimaan Beasiswa dengan Metode SAW (Simple Additive Weighting). Jurnal Teknologi Informasi DINAMIK Volume 16, No.2, Juli 2011 : 171176 ISSN : 08549524 , 173.

\section{KESIMPULAN}


[6] Adyanata Lubis, S.Kom., M.Kom. (2016). BASIS DATA DASAR UNTUK MAHASISWA ILMU KOMPUTER. Yogyakarta: CV. BUDI UTAMA.

[7] Moch Irfandi Susanto, Eko Darwiyanto, \& Gede Agung Ary Wisudawan. (2015). PENGUKURAN SOFTWARE METRIC TERHADAP IMPLEMENTASI FRAMEWORK LARAVEL PADA PEMBANGUNAN APLIKASI BERBASIS WEB. Studi Kasus : Jurnal Logic ISSN: 2355-9365, 7734.

[8] Herny Februariyanti, \& Eri Zuliarso. (2012). Rancang Bangun Sistem Perpustakaan untuk Jurnal Elektronik. Jurnal Teknologi Informasi DINAMIK Volume 17, No.2, Juli 2012 : 124-132 ISSN : 0854-9524, 128-129.

[9] Febrina Sari. (2018). METODE DALAM PENGAMBILAN KEPUTUSAN. Yogyakarta: CV. BUDI UTAMA.

[10] Arie Setya Putra, Desi Rahma Aryanti, \& Indah Hartati. (2018). Metode SAW (Simple Additive Weighting) sebagai Sistem Pendukung Keputusan Guru Berprestasi ( Studi Kasus : SMK Global Surya). 86. 